\title{
PROFESSORES: ENTRE SABERES E PRÁTICAS
}

\author{
Ana Maria Ferreira da Costa Monteiro*
}

O professor é aquele que ensina alguma coisa a alguém.

\begin{abstract}
RESUMO: A relação dos professores com os saberes que ensinam, constituinte essencial da atividade docente e fundamental para a configuração da identidade profissional, tem merecido pouca atenção de pesquisadores em educação. $\mathrm{O}$ objetivo deste artigo é discutir as possibilidades teóricas provenientes da articulação das categorias de análise "saber docente" e "conhecimento escolar" para a pesquisa das relações dos professores com os saberes que ensinam, categorias essas que levam em conta a especificidade da ação educativa e contribuem para o desenvolvimento de uma epistemologia da prática docente, distinta daquela que fundamenta o conhecimento científico, possibilitando a realização de pesquisas que possam efetivamente enfrentar os desafios apresentados com instrumental teórico apropriado.
\end{abstract}

Palavras-chave: saberes docentes, formação de professores, saberes escolares.

\section{Introdução}

A relação dos professores com os saberes que ensinam, constituinte essencial da atividade docente e fundamental para a configuração da identidade profissional, tem merecido pouca atenção de pesquisadores em educação voltados para outros aspectos igualmente importantes da atividade educativa, tais como as questões relacionadas à aprendizagem, aos aspectos culturais, sociais e políticos envolvidos.

Autores norte-americanos, inclusive, denunciam com o "missing paradigm" a inexistência de pesquisas sobre as matérias dos conteúdos

\footnotetext{
* Professora de Didática e Prática de Ensino de História da Faculdade de Educação da Universidade Federal do Rio de Janeiro (UFRJ) e doutoranda em Educação na Pontifícia Universidade Católica do Rio de Janeiro (Puc-Rio). E-mail: anamont@ufrj.br
} 
ensinados, ou seja, sobre o processo através do qual o conhecimento do professor se transforma em conteúdo de instrução (Shulman, 1986, p. 6).

Essa relação foi considerada e estudada por longo tempo dentro do paradigma da racionalidade técnica que, buscando a eficácia através do controle científico da prática educacional, trabalhava com a concepção de professor como um instrumento de transmissão de saberes produzidos por outros. Assim, o saber científico encontra(va) no professor um profissional habilitado - com a sua competência técnica - para adequá-lo, ou diluí-lo, (ou distorcê-lo, se ineficiente), para que seja (fosse) aprendido pelos alunos que, assim educados, e disciplinados, "evoluiriam para uma vida melhor".

Ainda presente no imaginário e prática social de muitos educadores, esta concepção tem sido questionada e criticada por aqueles que apontam a simplificação operada por este raciocínio que: nega a subjetividade do professor como agente no processo educativo; ignora o fato de que a atividade docente lida com, depende de e cria conhecimentos tácitos, pessoais e não sistemáticos que só podem ser adquiridos através do contato com a prática; ignora os estudos culturais e sociológicos que vêem o currículo como terreno de criação simbólica e cultural; e que ignora, também, todo o questionamento a que tem sido submetido o conhecimento científico nas últimas décadas.

Além disso, seja no chamado modelo diretivo "tradicional", que privilegia a relação professor-saber, fundamentado na racionalidade técnica, como naquele não diretivo, que privilegia a relação aluno-saber, o saber não é questionado. É, geralmente, um conhecimento universal que está posto, nos currículos ou livros didáticos, para ser ensinado. Discute-se muito os aspectos relacionais, importantes no processo, a forma de se incorporar os saberes e interesses dos alunos, mas em relação aos saberes ensinados, as preocupações são apenas de ordem de organização e didatização.

As pedagogias não-diretivas, "libertadoras", que radicalmente assumiam o questionamento dos saberes dominantes e valorizavam os saberes populares em nome da libertação ou emancipação dos grupos dominados, muitas vezes levaram a um esvaziamento da dimensão cognitiva do ensino que, em alguns casos, se restringiu a reproduzir o senso comum, com conseqüências perversas para os grupos subalternos que pretendiam libertar.

Nos últimos anos, no entanto, esforços têm sido realizados por pesquisadores em educação, com o objetivo de refinar o instrumental teórico disponível para realizar investigações que possam dar conta dessas novas questões cuja complexidade desafia os paradigmas vigentes. 
Nesse contexto, foi criada a categoria "saber docente", que permite focalizar as relações dos professores com os saberes que dominam para poder ensinar e aqueles que ensinam, sob uma nova ótica, ou seja, mediadas por e criadoras de saberes práticos, que passam a ser considerados fundamentais para a configuração da identidade e competência profissionais (Tardif, Lessard e Lahaye, 1991; Perrenoud, 1993, 1999; Therrien, 1996; Tardif, 1999; Moreira, Lopes e Macedo, 1998).

Acreditamos, no entanto, que mesmo esses trabalhos, que representam um avanço significativo para a compreensão da especificidade da ação docente, ainda se ressentem da ausência de pesquisas que direcionem seu foco de análise mais diretamente sobre a relação dos professores com os saberes que ensinam, tarefa esta que, certamente, demanda um esforço de especialistas das diferentes áreas de conhecimento específico, em trabalhos individualizados e coletivos, que possam melhor esclarecer essa relação tão valorizada pelos professores (principalmente aqueles que atuam no segundo segmento do ensino fundamental e no ensino médio) e, ao mesmo tempo, tão ausente de seus comentários e conversas cotidianas e profissionais. ${ }^{1}$

Como afirma Develay, tanto numa pedagogia que valoriza a ação docente de ensino do professor, como naquela em que o professor é visto como um mediador da aprendizagem dos alunos, sempre existem conteúdos a serem apropriados. Esse domínio pelo professor dos conteúdos a ensinar implica ir além do seu conhecimento, tornando necessário o desenvolvimento do que ele chama "competência de natureza epistemológica" - domínio da matriz disciplinar (Develay, 1995, p. 12), ou de procedimentos de transposição didática (Chevallard, 1991).

Por outro lado, pesquisadores preocupados com a especificidade da experiência educativa escolar têm trabalhado com a categoria "conhecimento escolar", referida como aquela que designa um conhecimento com configuração cognitiva própria, relacionado mas diferente do saber científico de referência, e que é criado a partir das necessidades e injunções do processo educativo, envolvendo questões relativas à transposição didática, ao conhecimento de referência e cotidiano, bem como à dimensão histórica e sociocultural numa perspectiva pluralista (Develay, 1995; Forquin, 1992; Chevallard, 1991; Goodson, 1998; Lopes, 1999).

A abordagem com base nessa categoria, que tem como foco primordial o conhecimento escolar em si mesmo e não o conhecimento mobilizado pelo professor, o que sugere a possível personalização ou particularização, permite avançar em relação às análises que, tendo o conheci- 
mento científico como padrão de referência de qualidade, induziram a uma acirrada e perversa desqualificação do trabalho dos professores, da educação escolar, ignorando sua especificidade do ponto de vista cultural.

Nesse artigo, temos como objetivo discutir as possibilidades teóricas provenientes da articulação das categorias de análise "saber docente" e "conhecimento escolar" para a pesquisa das relações dos professores com os saberes que ensinam, categorias de análise essas que, em nosso entender, abrem perspectivas promissoras para a melhor compreensão dos processos envolvidos.

Na primeira parte, fazemos uma análise das contribuições de alguns autores que operam com a categoria de saber escolar. Na segunda parte, analisamos proposições de autores que operam com a categoria de saber docente. Na terceira e última parte, fazemos uma discussão das possibilidades de articulação dessas propostas e levantamos algumas questões que revelam riscos e desafios a serem considerados com cautela durante a efetivação de uma pesquisa pautada por essas premissas, bem como alternativas promissoras suscitadas.

\section{O saber escolar}

A categoria de análise "conhecimento escolar" surgiu no contexto dos estudos que investigam a relação entre escola e cultura, bem como o papel desempenhado pela escola na produção da memória coletiva, de identidades sociais, e na reprodução das relações de poder, através de seus mecanismos e estratégias de "seleção cultural escolar".

Esses estudos, voltados para as questões relativas ao currículo, são tributários de trabalhos desenvolvidos por autores ingleses da chamada Nova Sociologia da Educação, a partir da proposta de Raymond William (1961) de pensar a cultura como "tradição seletiva", processo de decantação e de reinterpretação da herança deixada pelas gerações anteriores.

A sociologia do currículo foi aos poucos associada a um programa de crítica político-cultural radical, tendo na obra Knowledge and Control (Young, 1971) um verdadeiro manifesto que propunha a análise do currículo, ou seja, dos modos de seleção, legitimação, de organização e distribuição dos saberes escolares como a primeira tarefa de toda sociologia da educação (Forquin, 1996).

$\mathrm{Na}$ década de 1980, esses estudos desdobraram-se em três vertentes principais. Uma delas voltou-se para o estudo do chamado "currí- 
culo real", isto é, aquilo que é efetivamente ensinado nas salas de aula, por oposição ao "currículo formal" ou "oficial" tal como aparece nos programas dos cursos. Essa proposta tinha como base a idéia de que o currículo é um terreno de produção e criação simbólica e cultural, e não uma correia transmissora de uma cultura produzida em outro local, por outras pessoas, para as novas gerações, passivas e meramente receptoras. Os estudos buscavam, portanto, captar os processos de criação e produção de sentidos, significações e sujeitos nas escolas e salas de aula (Perrenoud, 1984; Isambert-Jamati, 1990).

Outra vertente, desenvolvida principalmente nos Estados Unidos e Grã-Bretanha, voltou-se para o estudo do chamado "currículo oculto", ou seja, conjunto de competências ou de disposições que se adquire na escola por experiência, impregnação, familiarização ou inculcação difusas, em contraste com aquilo que se aprende através de procedimentos pedagógicos explícitos ou intencionais (Apple, 1980).

Uma terceira vertente voltou-se para a investigação sobre o processo de constituição do conhecimento escolar, o que implicou a adoção de uma perspectiva histórica e deu origem a um novo campo de estudos no âmbito da História da Educação: a História das Disciplinas Escolares. Nesse campo se destaca, em língua francesa, o trabalho de André Chervel "História das disciplinas escolares: reflexões sobre um campo de pesquisa" publicado na França em 1988 e no Brasil em 1990 e, em língua inglesa, os trabalhos de Ivor Goodson (1993; 1998), autor que tem se dedicado a estudar como nascem e evoluem as matérias de ensino.

Tanto Chervel como Goodson, na opinião de Forquin, "abrem verdadeiramente caminhos novos à reflexão sociológica sobre o currículo, as matérias escolares, os conteúdos e as práticas de ensino." (1992, p. 40). Essa opinião é corroborada por Tomaz Tadeu da Silva, que destaca Goodson como o autor que tem efetivamente cumprido a "promessa investigativa" da Nova Sociologia da Educação, de expor a arbitrariedade dos processos de seleção e organização do conhecimento escolar e educacional, até então não realizada (Silva in Goodson, 1998, p. 7).

No âmbito dos estudos dos processos de constituição do conhecimento escolar, uma outra vertente reúne autores que têm pesquisado os chamados processos de transposição didática, ou seja, a passagem do saber sábio, de referência ou científico, ao saber ensinado, ${ }^{2}$ considerando que há uma especificidade em sua constituição que o distingue do saber de referência. Nessa perspectiva, o conhecimento escolar, embora tenha sua origem no conhecimento científico ou em outros saberes ou 
materiais culturais disponíveis, não é mera simplificação, rarefação ou distorção deste conhecimento. É um conhecimento com lógica própria, que faz parte de um sistema - o sistema didático - que tem relação com o saber de referência que Ihe dá origem e cuja constituição - processo e resultado da transposição didática - pode ser objeto de estudo científico através de uma epistemologia própria (Chevallard, 1991, p. 14).

Chevallard chama a atenção para o fato de que a transposição didática não é realizada pelos professores eles mesmos e, sim, por aqueles técnicos, representantes de associações, militantes, que compõem a noosfera, e que efetivamente realizam a passagem do saber sábio ao saber ensinado, em diferentes momentos, quando surge a necessidade de sua renovação ou atualização. Os professores trabalham na transposição didática, não fazem a transposição didática. Quando o professor intervém para escrever a variante local do texto do saber que ele chama seu curso, a transposição didática já começou há muito tempo (1991, p. 20).

Este autor, que oferece uma contribuição muito instigante ao trabalhar com o conceito de transposição didática, oferece um instrumental teórico para análise da especificidade da cultura escolar, mas, nos parece, ainda apresenta uma visão muito presa ao universo acadêmico que precisa ser ampliada.

Nesse sentido, Lopes chama a atenção para o fato de que "os processos de seleção e legitimação não são construídos a partir de critérios exclusivamente epistemológicos ou referenciados em princípios de ensino-aprendizagem, mas a partir de um conjunto de interesses que expressam relações de poder da sociedade como um todo, em um dado momento histórico. Assim, atuam sobre o processo de seleção cultural da escola, em relações de poder desiguais, o conjunto de professores, aqueles que fazem parte do contexto de produção do conhecimento de uma área e a comunidade de especialistas em educação. Atuam igualmente inúmeras outras instâncias culturais, políticas e econômicas de uma sociedade, que atuam direta ou indiretamente sobre a escola, sobre a formação e atualização de professores e sobre a produção de conhecimentos na área específica e educacional." (Lopes, 1998, p. 3).

Ou, como afirma Tomaz Tadeu, "o processo de fabricação do currículo não é um processo lógico, mas um processo social, no qual convivem lado a lado com fatores lógicos, epistemológicos, intelectuais, determinantes sociais menos 'nobres' e menos 'formais', tais como interesses, rituais, conflitos simbólicos e culturais, necessidades de legitimação e de controle, propósitos de dominação dirigidos por fatores ligados à classe, 
à raça, ao gênero" (Silva in Goodson, 1998, p. 8) e que exercem grande influência na constituição de identidades sociais no mundo contemporâneo.

Outros, como Forquin (1996), questionam se "o modelo da transposição" didática é universalmente aplicável, e se é ele que melhor explica a "lógica profunda" do currículo. Caillot (1996, p. 23) revela que o conceito de transposição didática é questionado por estudiosos da didática de outras disciplinas escolares que contestam o fato do saber sábio ser a única referência/fonte para o saber ensinado. Existem saberes ligados às práticas sociais e lingüísticas que não pertencem ao saber acadêmico elaborado pela comunidade científica e que fazem parte da elaboração do saber escolar. O contexto social, as escolhas econômicas ou políticas vão ter grande influência nas opções didáticas.

Caillot comenta também que no caso das ciências sociais, mais especificamente a história e a geografia, o significado é fundamental, havendo possibilidade de existência de diferentes versões e interpretações. Citando Audigier, Crémieux e Tutiaux-Guillon (1994), ele mostra como o saber escolar não "funciona" como os saberes sábios, constituindo estes dois tipos de saberes diferentes. Os saberes escolares são regidos pelos constrangimentos escolares em si mesmos e pelas finalidades que a escola lhes dá.

Esses autores, ao questionar um certo "mecanicismo" presente na obra de Chevallard, confirmam, por outro lado, a diferenciação entre os saberes, aspecto com o qual concordamos. É preciso, em nosso entender, realizar pesquisas que possibilitem averiguar o potencial e limites desta categoria de análise.

Embora não seja objeto principal de suas preocupações, voltadas primordialmente para a ação dos professores, Schön faz referência ao saber escolar que, em sua concepção,

é um tipo de conhecimento que os professores são supostos possuir e transmitir aos alunos. É uma visão dos saberes como fatos e teorias aceites, como proposições estabelecidas na sequência de pesquisas. Para este autor, o saber escolar é aquele tido como certo, significando uma profunda e quase mística crença em respostas exatas. É molecular, feito de peças isoladas, que podem ser combinadas em sistemas cada vez mais elaborados de modo a formar um conhecimento avançado. A progressão dos níveis mais elementares para os níveis mais avançados é vista como um movimento das unidades básicas para a sua combinação em estruturas complexas de conhecimento. (1995, p. 81) 
Para Schõn, o saber escolar é o conjunto de "representações formais" ${ }^{3}$ A citação é longa mas é apresentada aqui para revelar uma concepção sobre o saber escolar que surge de preocupações com o saber do professor e não com o saber escolar propriamente dito. A visão do saber escolar como molecular, certo, fatual, categorial e privilegiado (problemas com seu aprendizado são exclusivamente de responsabilidade dos alunos) é apresentada como um fato que pode ser transformado, se for possível mudar a maneira como os professores se relacionam com seus alunos e sua profissão. Se eles se tornarem profissionais reflexivos e conseguirem modificar a burocracia da escola, essas mudanças poderão viabilizar um ensino onde os saberes serão contextualizados e relacionados com a vida cotidiana dos alunos.

A proposta de Schön é diferente das demais, também por que seu ponto de partida para analisar o saber escolar é o professor e sua ação. Não cita, portanto, nesse texto, documentos curriculares ou a relação do saber escolar com o saber de referência.

Outro autor que destacamos é Develay (1995) para quem a essência da nova profissionalidade dos professores é o domínio dos saberes que ensinam, domínio este que, para ele, é de natureza epistemológica, ou seja, corresponde a um olhar crítico sobre os princípios, métodos e conclusões de uma ciência (preocupações semelhantes às de Shulman). Para Develay, o olhar epistemológico é reflexivo, possibilitando que nos debrucemos sobre o saber produzido (lembra Schön), gerando um saber de alto nível que o profissional deve oferecer através dos muitos conteúdos que ensina. Não é o resultado de uma acumulação somativa de informações, mas a capacidade para lidar com eles - transformar os conhecimentos pessoais em saberes (Develay, 1995, p. 12).

Citando Astolfi (1992) e Delbos e Jorion (1984), ele afirma que os saberes escolares são, por natureza, saberes proposicionais, ou seja, limitam-se a enunciar os conteúdos, sob a forma de proposições logicamente conectadas. Não são teóricos nem práticos. ${ }^{4}$ Develay questiona a formulação de Chevallard, afirmando a necessidade de se considerar os saberes da prática social, além do saber sábio, para efeito do estudo da transposição didática, e da necessidade de se levar em conta o processo de axiologização concomitantemente com o de didatização, porque elemento estruturante do saber escolar (a dimensão educativa ou a razão pedagógica).

Concluindo, ele chama a atenção para a necessidade de identificar na disciplina escolar o seu princípio de inteligibilidade, seu paradigma que ele propõe seja chamado de matriz disciplinar e que organiza a tota- 
lidade dos conteúdos num conjunto coerente (1995, p. 26-27). A identificação do paradigma disciplinar é fundamental porque ele determina as tarefas que serão desenvolvidas com os alunos, os conhecimentos declarativos a ensinar e os conhecimentos procedimentais correspondentes.

Como podemos perceber, a questão da constituição do conhecimento escolar é bastante complexa, envolvendo diversos aspectos relacionados tanto às suas fontes, referências de origem, como àqueles relacionados com a dinâmica sociocultural interna e externa à escola. Essa questão, que se coloca na intersecção entre a cultura escolar e os chamados constrangimentos didáticos, abre, em nosso entender, perspectivas instigantes que possibilitam abordagens inovadoras para o estudo dos fenômenos característicos da educação escolar.

\section{O saber docente}

A crítica à racionalidade técnica, que orientou e serviu de referência para a educação e socialização dos profissionais em geral e dos professores em particular durante grande parte do século XX, gerou uma série de estudos e pesquisas que têm procurado superar a relação linear e mecânica entre o conhecimento técnico-científico e a prática na sala de aula. Os limites e insuficiências dessa concepção levaram à busca de novos instrumentos teóricos que fossem capazes de dar conta da complexidade dos fenômenos e ações que se desenvolvem durante atividades práticas.

Diferentemente do que propõe a racionalidade técnica, as pesquisas começaram a revelar que

o professor intervém num meio ecológico complexo, num cenário psicológico vivo e mutável, definido pela interação simultânea de múltiplos fatores e condições. Nesse ecossistema, o professor enfrenta problemas de natureza prioritariamente prática, que, quer se refiram a situações individuais de aprendizagem ou formas de comportamentos de grupos, requerem um tratamento singular, na medida em que se encontram fortemente determinados pelas características situacionais do contexto e pela própria história da turma enquanto grupo social. (Gómez, 1995, p. 102)

As pesquisas que têm investigado esse conhecimento tácito, elaborado e mobilizado durante a ação pelos professores e, também, por qualquer outro profissional prático (reconhecendo-se as especificidades 
de cada fazer), possibilitaram o desenvolvimento de uma epistemologia da prática que abre perspectivas muito promissoras aos estudos do campo educacional.

Esses estudos somam-se àqueles que têm como pressuposto a crítica à idéia de que uma das origens das dificuldades encontradas no campo educacional é a desqualificação e a incompetência dos professores, e que se voltam para a questão da profissionalização, buscando compreender sua especificidade e constituição através dos processos de socialização, identificando nos saberes os aspectos que podem melhor definir e fortalecer a identidade e autonomia profissional.

No bojo desses estudos foi criada a categoria "saber docente" que busca dar conta da complexidade e especificidade do saber constituído no (e para o) exercício da atividade docente e da profissão (Schön, 1983, 1995; Enguita, 1991; Tardif, Lessard e Lahaye, 1992; Perrenoud, 1993; Popkewitz, 1995; Gómez, 1995; Develay, 1995; Lüdke, 1995, 1996, 1998; Moreira, 1998; Tardif, 1999).

Entre os autores que têm se debruçado sobre a questão dos saberes que os professores mobilizam quando ensinam, destacaremos Tardif, Lessard e Lahaye (1991); Perrenoud (1993, 1996); Schön (1995); Shulman (1996); Tardif (1999), buscando identificar aspectos e características de seus trabalhos que representam, em nosso entender, contribuições bastante significativas, bem como algumas diferenças que percebemos em suas proposições e análises.

Tardif, Lessard e Lahaye (1991) chamam a atenção para o fato de que o saber docente é plural, estratégico e desvalorizado, constituindo-se em um amálgama, mais ou menos coerente, de saberes oriundos da formação profissional, dos saberes das disciplinas, dos currículos e da experiência. Os primeiros têm sua origem na contribuição que as ciências humanas oferecem à educação e nos saberes pedagógicos (concepções sobre a prática educativa, arcabouço ideológico, algumas formas de saber-fazer e algumas técnicas) (1991, p. 219). Os saberes das disciplinas são aqueles difundidos e selecionados pela instituição universitária, correspondendo aos vários campos de conhecimento; os saberes curriculares, os quais a instituição escolar apresenta como aqueles a serem ensinados, resultado de um processo de seleção cultural ou de transposição didática, como quer Chevallard. ${ }^{5}$

Os saberes da experiência são os constituídos no exercício da prática cotidiana da profissão, fundados no trabalho e no conhecimento do meio. "São saberes que brotam da experiência e são por ela va- 
lidados. Incorporam-se à vivência individual e coletiva sob a forma de habitus e de habilidades, de saber fazer e de saber ser." (1991, p. 220).

"Esses saberes não provêm das instituições de formação ou dos currículos, esses saberes não se encontram sistematizados no quadro de doutrinas ou teorias: eles são saberes práticos (e não da prática: eles não se aplicam à prática para melhor conhecê-la, eles se integram a ela e são partes constituintes dela enquanto prática docente) [...] são a cultura docente em ação." (1991, p. 228) (grifo nosso).

Esses autores, ao realizar o trabalho de análise do saber docente, destacam sua complexidade, demonstrando seu caráter plural (grifo nosso). É interessante observar que eles buscam superar o modelo da racionalidade técnica chamando a atenção para a existência dos saberes da experiência, que não são para e sim da prática, aqueles que têm origem na prática cotidiana do professor em confronto com as condições da profissão.

Trabalham com a categoria de habitus de Bourdieu, como disposições adquiridas na e para a prática real, e que permitem ao professor enfrentar os desafios imponderáveis da profissão, constituindo a condição básica para um novo profissionalismo.

Os saberes da experiência surgem a partir da articulação, reorganização dos demais. Os autores afirmam que "os saberes da experiência não são saberes como os demais, eles são, ao contrário, formados de todos os demais, porém retraduzidos, 'polidos' e submetidos às certezas construídas na prática e no vivido." (1991, p. 232).

Ao procurar revelar a diversidade de sua elaboração em relação aos demais saberes constituintes do saber docente, os autores deixam um pouco vaga a sua formulação. Buscando mostrar que esses saberes não são completamente subjetivos, eles comentam o processo de criação de consensos parciais quando da partilha de certezas e conclusões entre os pares no confronto de saberes, processo este que acaba por conferir objetividade aos saberes da experiência. Mesmo assim, identificamos uma certa ambigüidade na formulação que busca avançar para a superação do modelo da racionalidade técnica: os autores apontam os saberes que serão aplicados na prática e distinguem aqueles saberes da prática, que surgem na prática, na experiência e que, "constituem o núcleo vital do saber docente, aquilo que possibilita aos professores transformar as relações de exterioridade com os saberes em relações de interioridade com sua prática." (1991, p. 232). 
A ambigüidade reside no fato de que, em sua formulação, os saberes da experiência acabam sendo tomados como se fossem novos saberes a serem utilizados. O saber docente é o saber da experiência ou é a soma dos quatro saberes citados anteriormente? Considerando-o "o amálgama mais ou menos coerente dos saberes da formação profissional, dos saberes das disciplinas, dos saberes curriculares e dos saberes da experiência" (1991, p. 218) não se resgata, de certa forma, o viés da racionalidade técnica?

Destacamos nesses autores o fato de valorizarem os saberes da prática - cultura docente em ação - e que, assim, deixa de ser vista como instância inferior, "errada ou distorcida", para se transformar em núcleo vital do saber docente.

Em texto de 1999, Tardif aprofunda a análise das características do saber docente, apresentando uma proposta para o estudo da epistemologia da prática profissional onde são considerados "os saberes utilizados realmente pelos profissionais em seu espaço de trabalho cotidiano para desempenhar todas as suas tarefas" (Tardif, 1999, p. 15), avançando na valorização do saber da experiência. Segundo o autor, os saberes profissionais são saberes da ação, saberes do trabalho e no trabalho, o que os distingue dos saberes universitários - científicos (?). São temporais, plurais e heterogêneos, personalizados e situados, carregando consigo as marcas do seu objeto que é o ser humano (os alunos).

Nesse sentido, a prática profissional não é um local de aplicação dos saberes universitários mas, sim, de "filtração", onde eles são transformados em função das exigências do trabalho (p.17). Essas características identificadas pelo autor permitem superar a visão do professor como um "idiota cognitivo" (p. 19), dependente e determinado por estruturas sociais, pelo inconsciente ou cultura dominante, representando uma contribuição significativa para avançarmos na conquista da autonomia profissional.

Esse trabalho reforça a necessidade de revisão dos processos de formação de professores, ao destacar as diferenças entre o contexto universitário, voltado para a pesquisa acadêmica, e aquele que deve servir para a formação profissional de constituição epistemológica com características diferentes.

Schön é outro autor que oferece uma contribuição importante para o estudo do saber dos professores que, segundo ele, criam um conhecimento específico e ligado à ação, que só pode ser adquirido através do contato com a prática. É um conhecimento pessoal, tácito e não sistemático, espontâneo, 
intuitivo, experimental, quotidiano, do tipo que leva a pessoa a agir sem saber como age, em concepção oposta à da racionalidade técnica.

Coerentemente com sua proposta voltada para a ação, ele criou a categoria de professor-reflexivo e o conceito de reflexão-na-ação, segundo o qual o professor analisa e interpreta a sua própria realidade no ato, e o de reflexão-sobre-a-ação, que implica o olhar retrospectivo e a reflexão sobre o que foi realizado.

Sua proposta radicaliza a questão da importância da ação prática que quase se autonomiza, podendo fazer sugerir o risco de volta ao espontaneísmo do voluntarismo empirista.

Outro autor que oferece uma contribuição importante é Perrenoud. Preocupado em entender a atividade docente, ele discute suas características particulares que oscilam entre a rotina e a improvisação regulada, num movimento que implica uma complexidade que a racionalidade técnica não tem condições de dominar. Apoiado em Chevallard, ele chama a atenção, também, para as transformações operadas nos saberes para serem ensinados, o processo de transposição didática que se baseia numa epistemologia que fixa o estatuto desse saber, do erro, do esforço, da atenção, da originalidade, das perguntas e respostas (1993, p. 24).

Em outro trabalho mais recente, aprofundando a reflexão sobre a profissão docente (1996), Perrenoud alerta para os limites e riscos de se analisar os recursos cognitivos de uma pessoa que desenvolve uma ação apenas em termos de saberes e conhecimentos (para ele os dois termos são intercambiáveis). Do seu ponto de vista, é necessário enfrentar o problema das competências que englobam os saberes, mas não se reduzem a eles. Competências são capacidades de ação, que mobilizam saberes para a ação, que estabelecem relações com os saberes teóricos que não são de reverência ou de dependência, mas ao contrário, são críticas, pragmáticas, até mesmo oportunistas (1996, p.135).

Perrenoud, em nosso entender, ao propor a utilização do conceito de competência, apresenta uma proposta consistente para se pensar o conhecimento tácito da prática do professor. Ele consegue discutir e relativizar o papel dos saberes discutindo as várias facetas do problema tais como a relação entre saberes sábios e científicos, saberes científicos e saberes da experiência (mostrando que eles não são opostos, mas que o saber científico pesquisa e busca objetos na experiência). "A verdadeira distinção é entre saberes sábios e saberes do senso comum. Tanto um como o outro se enraízam na experiência humana, mas de forma diferen- 
te." (1996, p. 142). Ele, de certa forma, critica Tardif quando este opõe os saberes da experiência aos saberes com origem nos saberes sábios.

$\mathrm{O}$ autor distingue saberes declarativos e procedimentais (que explicam como agir, fazer ou ser) das competências que podem vir a ser codificadas em saberes procedimentais. Saberes e conhecimentos são representações.

Perrenoud analisa, com base em Piaget, a noção de competência, utilizando o conceito de esquemas operatórios de percepção, avaliação, decisão ou de ação, portanto não são representações, são outra coisa, existem no estado prático (1996, p. 137). Os esquemas são a estrutura da ação. Ele utiliza também o conceito de habitus, conforme Bourdieu, conjunto de esquemas de que dispõe um ator.

Perrenoud, portanto, enriquece o potencial de análise. Da mesma forma que os demais, ele prioriza o conceito de saber da experiência ou da prática, estratégicos no trabalho do professor, mas oferece um instrumental conceitual mais rico para dar conta da complexidade (conceito por ele também utilizado) do saber docente. De acordo com ele, investigar e desenvolver as competências do professor não invalida ou nega o papel dos saberes. Muito pelo contrário, é preciso a aquisição de conhecimentos para serem mobilizados nas competências. O processo não é automático. $O$ domínio dos saberes não garante a competência. Cabe ao trabalho de pesquisa buscar melhor compreender como esse processo se realiza.

Outro trabalho que gostaríamos de mencionar é o de Shulman (1986), que estuda os diferentes tipos e modalidades de conhecimento que os professores dominam, configurando uma epistemologia própria. Sua contribuição é importante, em nosso entender, porque traz de volta ao centro da discussão a questão do conhecimento que os professores têm dos conteúdos de ensino e do modo como estes conteúdos se transformam no ensino.

Ele afirma que a atual separação entre conteúdos de ensino e conteúdos pedagógicos é um desenvolvimento recente na área da educação, e que tem levado docentes e pesquisadores a valorizar em seus trabalhos muito mais os aspectos de ordem psicológica e/ou metodológica, deixando de lado a relação orgânica com o conhecimento de referência e que é a fonte de exemplos, explicações e formas de lidar com os erros e mal entendidos dos alunos. Identificando essa questão como o "missing paradigm", ele se propõe investigar o que sabem os professores sobre os conteúdos de ensino, onde e quando adquiriram os conteúdos, como e por que se transformam no período de formação e como são utilizados na sala de aula. 
O autor distingue três categorias de conhecimento de conteúdos que se desenvolvem nas mentes dos professores:

O conhecimento da matéria do conteúdo refere-se à quantidade e organização do conhecimento por si mesmo na mente do professor. Para ele, nas diferentes áreas de conhecimento, os modos de discutir a estrutura de conhecimento são diferentes. Para bem conhecer os conteúdos é preciso ir além do conhecimento dos fatos e conceitos de um determinado domínio, sendo necessário compreender a estrutura da matéria utilizando, por exemplo, as categorias estrutura substantiva e estrutura sintática.

A estrutura substantiva é aquela na qual os conceitos básicos e princípios da disciplina estão organizados para incorporar os fatos.

A estrutura sintática de uma disciplina é o conjunto de modos pelos quais verdade ou falsificabilidade, validade ou invalidade são estabelecidas. A sintaxe é um conjunto de regras para determinar o que é legítimo num domínio disciplinar e o que quebra as regras.

O conhecimento pedagógico dos conteúdos é um segundo tipo de conhecimento de conteúdo, que vai além do conhecimento da matéria do assunto por si mesma para a dimensão do conhecimento da matéria do assunto para ensinar. Inclui as formas mais comuns de representação das idéias, as analogias mais poderosas, as ilustrações, os exemplos, explicações e demonstrações, ou seja, os modos de representar e formular o assunto de forma a torná-lo compreensível para os outros. Inclui também aquilo que faz a aprendizagem de um determinado assunto fácil ou difícil (aqui a pesquisa sobre o ensino coincide muito de perto com a pesquisa sobre a aprendizagem).

O conhecimento curricular é o conhecimento sobre o currículo, "é o conjunto de programas elaborados para o ensino de assuntos específicos e tópicos em um nível dado, a variedade de materiais instrucionais disponíveis relacionados a estes programas" e sobre o conjunto de características que servem tanto como indicações ou contra-indicações para o uso de um currículo em particular, ou programas em circunstâncias particulares (1986, p. 9-10).

Esse trecho nos permite indagar se, para Shulman, saber sábio e saber escolar são expressões de um mesmo saber. Ele não utiliza o conceito de transposição didática, cuja formulação é contemporânea ao seu texto, nem trabalha com a concepção nele subjacente. O conceito de conhecimento escolar com epistemologia diferente daquela do saber sábio não é mencionado e, portanto, ele não problematiza a historicidade do 
conhecimento curricular/escolar. Este é citado como conhecimento que os professores precisam dominar para ensinar, da mesma forma que um médico precisa conhecer os remédios disponíveis para serem receitados. Seria como que uma seleção feita do saber de referência para definir o que precisa ser ensinado. Mas não seriam os "conteúdos de conhecimento pedagógico" uma formulação que se aproxima do conceito implícito na formulação de conhecimento escolar? Ou seja, os conteúdos já adequados às finalidades educativas, e não mais os conteúdos científicos stricto sensu?

Shulman não trabalha, também, com o conceito de saber da experiência, mas essa dimensão é objeto de sua preocupação de duas maneiras. Primeiramente, quando ele afirma que os conhecimentos pedagógicos são "a forma particular de conhecimento dos conteúdos que englobam os aspectos dos conteúdos mais apropriados para o seu ensino" (op. cit., p. 9) (grifo nosso). Aqui, indiretamente, ele faz referência à ação, à prática.

A outra forma utilizada por Shulman para se referir ao saber da experiência, é através da classificação que ele faz dos conhecimentos necessários para os professores, e que ele chama de saber dos professores - "teacher knowledge" (saber dos professores? saber docente?), criado pela experiência dos professores ou "das formas do saber dos professores" ou seja, as formas pelas quais os saberes dos conteúdos, os saberes curriculares e os saberes pedagógicos podem ser ou estar organizados para serem ensinados aos professores (saber da experiência?) (p. 10-11). São três as categorias de Shulman (op. cit.):

O conhecimento proposicional, que é aquele relativo à investigação didática, que pode oferecer e que reúne três tipos de proposições: princípios, máximas e normas. Os princípios são oriundos de pesquisas empíricas; as máximas são oriundas da prática, não possuem confirmação científica (ex.: quebre um pedaço de giz antes de escrever para evitar que ele provoque ruídos no quadro); as normas referem-se aos valores, compromissos ideológicos e éticos de justiça, equidade etc.; eles não são teóricos nem práticos, mas sim normativos. Ocupam a essência do que o autor chama de saber dos professores. Eles guiam o trabalho do professor porque são eticamente ou moralmente corretos.

O conhecimento de casos relativo ao conhecimento de eventos específicos, exemplos que auxiliam a compreensão da teoria. Podem ser de três tipos: protótipos - exemplificam os princípios teóricos; precedentes expressam as máximas; e parábolas - expressam normas e valores. 
O conhecimento estratégico, que diz respeito a como agir em situações dilemáticas, contraditórias, onde princípios contradizem máximas e/ou normas.

Shulman desenvolve uma tipologia bastante elaborada que procura dar conta dos aspectos relativos aos conhecimentos utilizados e criados na atividade docente. Seu trabalho é anterior ao de Tardif, Lessard e Lahaye, mas podemos identificar na proposta destes autores algumas semelhanças com a de Shulman (conhecimentos das disciplinas, pedagógicos e curriculares, bem como os da prática). Eles inovaram ou simplificaram (?) ao criar a categoria saber docente como um amálgama dos demais. Cabe destacar, na proposta de Shulman, uma contribuição importante quanto aos instrumentos oferecidos para a investigação da ação dos professores, ou seja, o domínio dos saberes na ação.

\section{Entre saberes e práticas}

Lembrando Chervel (1990, p. 188), a escola é uma instituição que tem na instrução sua principal dimensão educativa, educa através da instrução. A crítica ao ensino tradicional, onde o saber ocupava um lugar quase sacralizado, pode explicar o certo abandono pelas questões relacionadas com os saberes ensinados. As pesquisas se concentraram, em grande parte, nas questões relacionadas à aprendizagem. O saber não era discutido, o problema estava no aprender. Não queremos dizer aqui que as pesquisas sobre aprendizagem não são necessárias. Certamente elas precisam ser desenvolvidas e oferecem contribuições relevantes para a compreensão dos processos educativos. No entanto, defendemos que investigar a epistemologia do conhecimento escolar e da prática do professor é fundamental e estratégico para a compreensão dos processos em jogo. Negá-la ou esquecê-la nos faz correr o risco de cair no retrocesso de propostas espontaneístas/populistas ou autoritárias para a educação.

Para o estudo das questões relacionadas aos saberes ensinados, acreditamos que é possível considerar, de forma articulada, as contribuições dos autores que trabalham com a categoria de conhecimento escolar, investigando o processo de transposição ou mediação didática, criador de conhecimento com características próprias (Chevallard, Lopes) e não apenas uma simplificação ou banalização do saber científico, e aquelas de autores que trabalham sobre o saber docente.

O reconhecimento do conceito de conhecimento escolar é uma proposta ousada e polêmica, mas promissora para o avanço na com- 
preensão dos processos educativos, possibilitando o rompimento de barreiras e limites postos por paradigmas transpostos do campo científico. ${ }^{6}$

Os autores que estudam os saberes dos professores, em sua maioria, estão mais preocupados com a questão da prática, do saber na ação. Selecionamos aqueles que, de alguma forma, reconhecem a especificidade do conhecimento escolar, mesmo que não abordem diretamente a questão da sua relação com o conhecimento científico.

Temos por hipótese que as adequações que geram o conhecimento escolar, seu contexto de produção e recepção, estão diretamente relacionadas com as necessidades e constrangimentos da prática profissional, o que permite articular essas duas categorias de análise para ampliar o instrumental teórico e poder dar conta do desafio proposto.

Por esse motivo, reconhecemos em Shulman a apresentação de propostas que merecem ser melhor investigadas e articuladas com as contribuições de Perrenoud sobre como as competências mobilizam os saberes utilizando os esquemas mentais e o habitus. Como os conteúdos ensinados são organizados e didatizados pelos professores? É na prática que eles aprendem a fazer isso? Ou os fundamentos teóricos dos saberes de referência atuam nessa mediação também? Reproduzem inconscientemente práticas interiorizadas?

Como já afirmamos anteriormente, podemos perceber em Tardif, Lessard e Lahaye algumas aproximações com Shulman. Mas Shulman aprofunda mais a discussão, apontando para as adequações ou transformações que o professor realiza ao ensinar os conteúdos ao longo de sua prática, enquanto Tardif, Lessard e Lahaye se concentram mais no comentário sobre o saber da experiência, identificando suas características relacionadas aos sujeitos em ação, sem mencionar aspectos relacionados aos saberes ensinados.

Reconhecemos, também, que, embora realizando abordagens teóricas distintas, há pontos de aproximação quando, por exemplo, Tardif, Lessard e Lahaye trabalham o conceito de "saber da experiência"; Perrenoud comenta a mobilização dos saberes através das competências; Shulman utiliza o conceito de "conhecimento pedagógico do conteúdo", ou seja, o conteúdo específico reelaborado para ser ensinado, o que nos faz lembrar do conceito de "objeto de ensino" de Chevallard; Develay utiliza o conceito de "matriz disciplinar" para se referir ao paradigma que torna o conhecimento coerente para ser ensinado e que é resultado de injunções didáticas e axiológicas, e que nos faz lembrar da "estrutura substantiva", utilizada por Shulman. 
A articulação das duas vertentes pode auxiliar a iluminação de aspectos ainda pouco conhecidos da epistemologia da prática relativos à mobilização dos saberes e competências que são ensinados e desenvolvidos nas escolas. Cabe realizar as pesquisas e testar seu potencial.

Recebido para publicação em 16 de janeiro de 2001.

\section{Notas}

1. Acreditamos que tanto do ponto de vista do trabalho de base disciplinar como nas tentativas voltadas para a interdiscplinaridade, esses estudos se fazem urgentes para que possamos lançar luz sobre aspectos ainda obscuros da prática docente. Muitas tentativas de reforma educacional fracassaram, em nosso entender, devido a um desconhecimento de características próprias da atividade docente, consideradas por técnicos e teóricos apriorísticamente como defeituosas e equivocadas e, portanto, necessariamente superadas. Deixavam, assim, de ser considerados artifícios já impregnados na cultura profissional, e utilizados para lidar com os constrangimentos e imperativos didáticos da cultura escolar que, de alguma forma, oferecem aos professores alternativas preciosas para lidar com situações imprevistas e imponderáveis que fazem parte do cotidiano escolar e que precisam ser controladas para a realização das tarefas propostas.

2. Segundo Forquin (1993), a noção de transposição didática enquanto reestruturação e reorganização dos conhecimentos selecionados pela escola foi enunciada, pela primeira vez, por Verret, em sua tese Les Temps des Études, defendida em 1975, na França. Posteriormente, Chevallard e Joshua (1982) e Chevallard (1991) estudaram a questão da transposição didática na Matemática, examinando a transformação sofrida pela noção matemática de distância entre o momento de sua construção por Frechet, em 1906, e o momento de sua introdução nos programas de geometria franceses.

3. "As representações figurativas implicam agrupamentos situacionais, contextualizados: as relações que se estabelecem na maior proximidade possível das experiências cotidianas. As formais implicam referências fixas, tais como linhas, escalas, mapas com coordenadas, medidas uniformes de distância: numa palavra, o saber escolar." (Schön, 1995, p. 85).

4. Os saberes teóricos são plásticos, flexíveis, maleáveis porque suscetíveis de serem utilizados em situações diversas; os saberes práticos são intrinsecamente ligados à condições de uso normais (Astolfi, 1992 apud Develay, 1995, p. 24-25).

5. Citamos aqui este conceito embora ele não seja utilizado por estes autores.

6. Não estamos aqui defendendo o abandono de uma postura científica para a realização desses estudos, mas sim uma postura científica que, no lugar de impor modelos prontos e apriorísticos, se instrumentalize para investigar o fenômeno educativo em sua especificidade. 


\section{TeaChers: BetWEen KNOWLEDGE AND PRACTICES}

ABSTRACT: Teacher's relations with the contents they teach, essential constituents of teaching activity and fundamental for the formation of professional identity, have not yet been paid the attention they deserve by researchers. This article aims to discuss the theoretical possibilities provided by the combination of the categories "teacher's knowledge" and "school knowledge" while researching teacher's relations with the contents they teach. Implicit in these categories is the understanding of the specificity of educational activity which helps the development of an epistemology of teaching practice, different from that inherent to scientific knowledge, allowing the development of research on teaching provided with the appropriate theoretical instruments to face the emergent challenges.

Key words: teacher's knowledge, teacher's education, knowledge, subject matter content knowledge.

\section{Referências bibliográficas}

CHERVEL, A. História das disciplinas escolares: Reflexões sobre um campo de pesquisa. Teoria e Educação no 2, Porto Alegre: Pannônica, 1990, p. 177-229.

CHEVALLARD, Y. La transposición didáctica. Del saber sabio al saber enseñado. Buenos Aires: Aique Grupo Editor, 1995.

DEVELAY, M. Savoirs scolaires et didactique des disciplines: Une encyclopédie pour aujourd'hui. Paris: ESF Editeur, 1995.

ENGUITA, M.F. A ambigüidade da docência: Entre o profissionalismo e a proletarização. Teoria e Educação no 4, Dossiê: "Interpretando o trabalho docente", Porto Alegre: Pannônica, 1991, p. 41-61.

FORQUIN, Jean-Claude. As abordagens sociológicas do currículo: Orientações teóricas e perspectivas de pesquisa. Educação e Realidade ํo 1, "Currículo e política de identidade", vol. 21, Porto Alegre: Universidade Federal do Rio Grande do Sul/Faculdade de Educação, 1996, p. 187-198.

. Escola e cultura. As bases sociais e epistemológicas do conhecimento escolar. Porto Alegre: Artes Médicas, 1993.

Saberes escolares, imperativos didáticos e dinâmicas sociais. Teoria e Educação, no 5, Porto Alegre: Pannônica, 1992, p. 28-49. 
GARCIA, C.M. A formação de professores: Novas perspectivas baseadas na investigação sobre o pensamento do professor. In: NÓVOA, A. (org.). Os professores e sua formação. Lisboa: Dom Quixote, 1995.

GÓMEZ, A.P. O pensamento prático do professor. A formação do professor como profissional reflexivo. In: NÓVOA, A. (org.). Os professores e sua formação. Lisboa: Dom Quixote, 1995.

GOODSON, I. Currículo: Teoria e história. 2ª ed., Petrópolis: Vozes, 1995.

- Tornando-se uma matéria acadêmica: Padrões de explicação e evolução. Teoria e Educação ํo 2, Porto Alegre: Pannônica, 1990, p. 230-254.

ISAMBERT-JAMATI, V. Les savoirs scolaires: Enjeux sociaux des contenus d'enseignement et de leurs réformes. Paris: Éditions Universitaires, 1990.

CAILLOT, M. La théorie de la transposition didactique est-elle transposable? In: RAISKY, C. e CAILLOT, M. (edit.). Au-delá des didactiques, le didactique. Débats autour des concepts federateurs. Paris: De Bœck, 1996.

LOPES, A.R.C. Conhecimento escolar: Ciência e cotidiano. Rio de Janeiro: Ed. UERJ, 1999.

Questões para um debate sobre o conhecimento escolar. Ensino de História, Revista do Laboratório de Ensino de História da UFF, no 3, vol. 3, out. 1999.

LÜDKE, M. "Socialização profissional de professores: As instituições formadoras". Relatório de pesquisa, Rio de Janeiro, PUC-Rio, 1998.

Sobre a socialização profissional dos professores. Cadernos de Pesquisa no 99. São Paulo: Fundação Carlos Chagas, 1996, p. 5-15.

. "A socialização profissional de professores. $3^{\circ}$ etapa: As instituições formadoras". Projeto integrado de pesquisa, coordenada pela Professora Menga Lüdke e desenvolvido no Departamento de Educação da PUC-Rio. Rio de Janeiro, julho, 1995.

. "Os professores e sua socialização profissional". Relatório de pesquisa, Departamento de Educação da PUC-Rio, Rio de Janeiro, dez. 1995.

MOREIRA, A.F.B. e SILVA, T.T. da (orgs.). Currículo, cultura e sociedade. São Paulo: Cortez, 1994.

MOREIRA, A.F.B., LOPES, A.C. e MACEDO, E. "Socialização profissional de professores: As instituições formadoras". Relatório de pesquisa. Rio de Janeiro, UFRJ, 1998. 
NÓVOA, A. Profissão professor. $2^{\mathrm{a}}$ ed. Porto: Porto Editora, 1995. (org.). Os professores e sua formação. Lisboa: Dom Quixote, 1995.

PERRENOUD, P. Dez novas competências para ensinar. Porto Alegre: Artes Médicas, 1999.

. Enseigner: Agir dans l'urgence, décider dans l'incertitude. Savoirs et compétences dans un métier complexe. Paris: ESF Editeur, 1996.

. Práticas pedagógicas, profissão docente e formação. Perspectivas sociológicas. Lisboa: Dom Quixote, 1993.

POPKEWITZ, T.S. Profissionalização e formação de professores: Algumas notas sobre a sua história, ideologia e potencial. In: NÓVOA, A. (org.). Os professores e sua formação. Lisboa: Dom Quixote, 1995.

SACRISTAN, J.G. Consciência e ação sobre a prática como libertação profissional dos professores. In: NÓVOA, A. Profissão professor. $2^{a}$ ed. Porto: Porto Editora, 1995, p. 63-92.

SANTOS, Lucíola L. de C.P. História das disciplinas escolares: Perspectivas de análise. Teoria e Educação no 2, Porto Alegre: Pannônica, 1990, p. 21-29.

SCHÖN, D. Formar professores como profissionais reflexivos. In: NÓVOA, A. (org.). Os professores e sua formação. Lisboa: Dom Quixote, 1995.

SHULMAN, L. Those who understand: Knowledge growth in teaching. Educational Researcher 15(2), 1986, p. 4-14.

SILVA, T.T. da. Apresentação. In: GOODSON, I. Currículo: Teoria e história. $2^{\mathrm{a}}$ ed. Petrópolis: Vozes, 1995.

TARDIF, M., LESSARD, C. e LAHAYE, L. Os professores face ao saber. Esboço de uma problemática do saber docente. Teoria e Educação no 4, Porto Alegre: Pannônica, 1991.

TARDIF, M. "Saberes profissionais dos professores e conhecimentos universitários. Elementos para uma epistemologia da prática profissional dos professores e suas conseqüências em relação à formação para o magistério". Rio de Janeiro, PUC-Rio, 1999 (mimeo).

VERRET, M. Le temps des études. Lille: Atelier de reproduction de thèses. France, 1975.

WILLIAMS, R. The long revolution. Londres: Chato and Windus, 1961.

YOUNG, M. Knowledge and Control. New Directions for the Sociology of Education. Londres: Collier-Macmillan, 1971. 